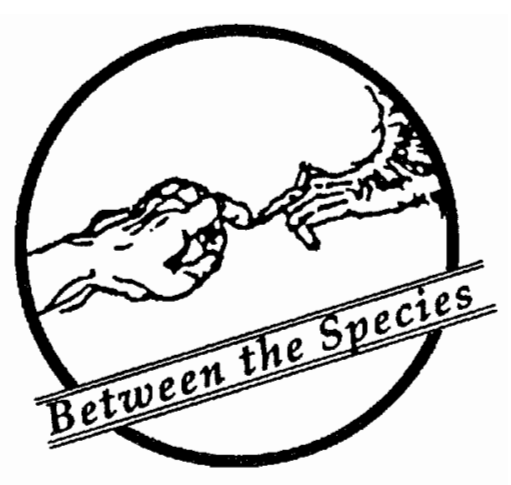

\title{
Animal Models in 'Exemplary' Medical Research: Diabetes as a Case Study
}

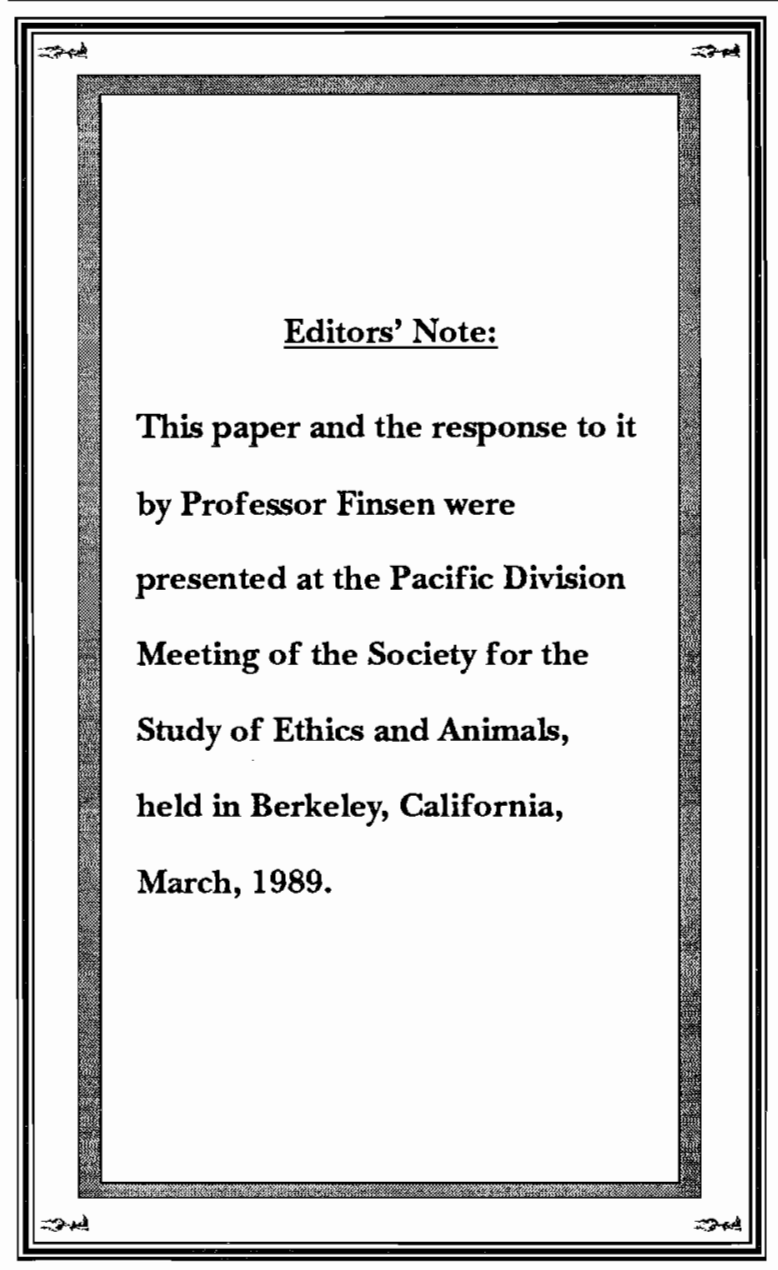

James Lindemann Nelson

St. John's University

\section{Introduction}

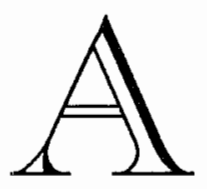

nyone trying to get clear about the morality of the use of animals in medical research immediately faces the following problem: it is immensely hard to get agreement on the value of the enterprise strictly for humans. H.J. McCloskey, for example, portrays the human stake in the issue as being of apocalyptic proportions: 
Without continued animal experimentation in the past, ... we should still be incapable of checking the ravages of septicemia, gangrene, diabetes, and a host of other diseases. Without continued experimentation we shall be exposed to the new strains and new diseases that continue to emerge, golden staphylococcal infection, Legionnaire's Disease, AIDS, and the very many other diseases that are emerging. ${ }^{1}$

But there are, of course, dozens of writers who opine that the decline in mortality due to infectious diseases had much more to do with refinement in hygiene and sanitation than with medical techniques based on animal research. ${ }^{2}$

Even on a much finer level of comparison, apparently contradictory views are not hard to find. Fred Davidson tells us that "the whole field of nutrition has its foundation firmly rooted in animal experimentation, which has led to the discovery of diet essentials (such as all the known vitamins)," while Sidney Gendin writes, "the foundation of nutritional science was the discovery of vitamins, and their role in health owes almost nothing to animal experimentation. ${ }^{m}$

When we consider the possibility of alternatives to the use of animal models, we find that those who are most insistent about the value of medical experimentation are least sanguine about potential alternatives. McCloskey, for instance, calls the suggestion that needed information could be gotten without animal experimentation "little short of irresponsible." ${ }^{\mathrm{N}}$ Dallas Pratt, on the other hand, maintains that research on several diseases is actually being slowed down by our reliance on in vivo techniques. ${ }^{6}$

In the light of all this, one might wonder whether the question of the prudence of animalbased medical research weren't at least as controversial as the question of its morality. Surely, insofar as such work is inessential - if we can easily make do without its contributions, or attain what results it does have to offer as well or better elsewise - then not only do the prospects for its successful moral defense pale to the point of invisibility, but the whole thing becomes a sterile ritual. My response to this uncertainty is to structure criteria for a kind of animal-based medical research which, if satisfied, would make the issue of a significant clash of important human and nonhuman interests hard to avoid. I am therefore interested in medical research which exhibits the following qualities:

1. it targets widespread, debilitating diseases;

2. it has an admirable track record in using animals to aid in our understanding and management of the disease; and

3. it is conducted according to humane standards as they are currently understood.

I refer to any investigation meeting these criteria as "exemplary" medical research, and conclude that any such research at least meets the test of prudence. Whether it passes the stricter test of morality is the matter I will explore here.

\section{Diabetes as a Case Study}

Diabetes mellitus may not be at all a disease of any drama, but research on its causes and cures seems a likely candidate for inclusion under the "exemplary research" rubric. For diabetes, while yet widespread and debilitating, is no longer a disease which is liable to condemn its victims to a lingering and painful death, and this outcome is as clearly traceable to animal research, and (until recently) to animals as a source of insulin, as anything is likely to be. Before 1921 diabetics had no better therapeutic recourse than to submit themselves to a severely restricted diet, which was calculated to walk the often fine line between the amount of nutrition a patient had to have to live, and the amount which would overtax her compromised metabolism, causing glycosuria, diabetic coma, and death. For severe diabetics this therapy never involved more than a brief extension of life, and it was never pleasant. "A quarter of a century after the discovery of insulin," writes Michael Bliss in his history of the research leading to the isolation of the hormone, "doctors were reminded of ... preinsulin diabetics when they saw the pictures of the survivors of Belsen and Buchenwald."

Insulin was discovered primarily through the contributions of the Canadian scientists Frederick Banting and Charles Best, in collaboration with J.J.R. Macleod, J.B. Collip, and several dogs. The dogs were rendered diabetic and then 
treated with extracts of their own atrophied pancreases. The discovery had immediate and continuing therapeutic payoff. Bliss estimates that in 1920 between 0.5 and 2.0 percent of the population of the industrialized countries was diabetic; in a 1974 article, Best estimated that 130 million lives had been saved by the discovery of insulin. ${ }^{8}$ There are today half a million insulindependent diabetics in the U.S. alone. Even stern critics of animal research, such as Peter Singer and Andrew Rowan, have cited diabetes research as having had great human value. ${ }^{9}$

But granted that diabetes was (and remains) widespread, and was (and to a lesser extent remains) debilitating, and that great strides against it were made through the use of animal research, it still remains to show that continued animal-based research on diabetes is of significance. Things are not as clear here - there have been no further miracle breakthroughs with the impact of the discovery of insulin - yet there is reason to think that important progress is being made.

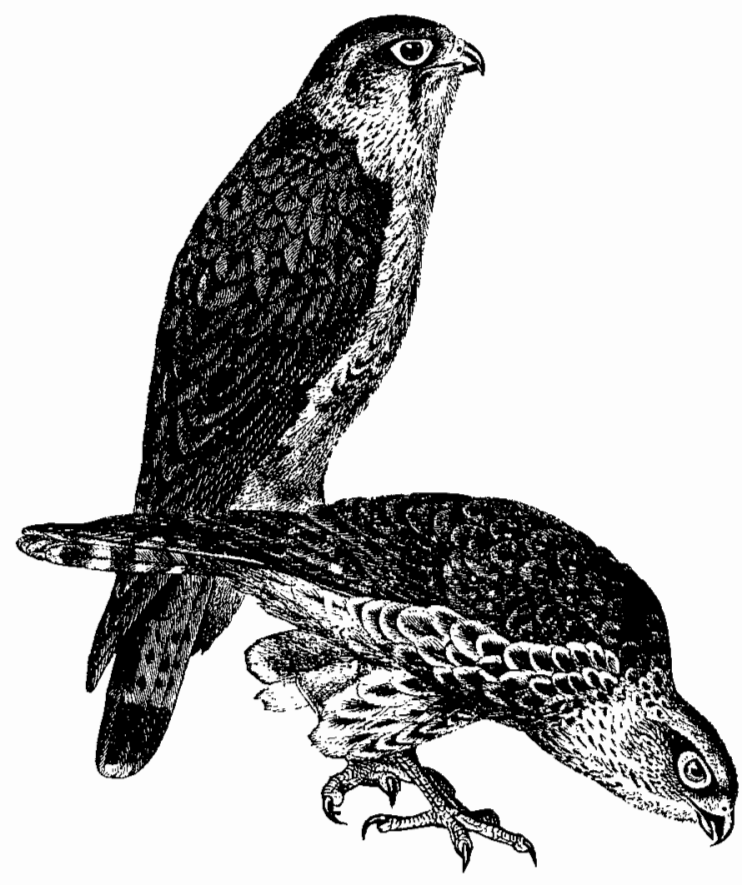

Although insulin has saved the lives of an immense number of people, it is not a cure; diabetes is still widespread and still debilitates. It is the seventh leading cause of death in the U.S., claiming about as many lives per year as arteriosclerosis or breast cancer, and about twice as many as hypertensive disease or leukemia. ${ }^{10}$ White males and females who are insulindependent suffer a mortality rate five to eleven times greater than that for nondiabetics of the same age; the mortality rate for black insulindependent diabetics is about twice as high as their white counterparts. ${ }^{11}$ In addition to the increased risk of death, many diabetics suffer greatly from nervous, vascular, and ocular complaints that often lead to such problems as blindness, loss of limbs, and impotence.

Ongoing work in diabetes research is concerned with its etiology, which is still imperfectly understood. It also addresses management of the physical consequences of long-term treatment of the diabetic state by exogenous insulin therapy, a problem medicine didn't face before 1921. And, of course, it seeks a cure. All this work uses various kinds of animal models. For example, the BB rat, a model of spontaneous diabetes, has provided evidence that diabetes is (or may be) an autoimmune disease; dogs are claimed to be useful models for the study of ocular complications typical of human diabetics; diabetic Yucatan miniature swine are prone to vascular complaints, a critical problem in human beings; and the size and longevity of primates allow longitudinal studies not feasible in smaller animals. ${ }^{12}$

That some of this work, at least, has therapeutic benefit is indicated by a 19 percent drop in the mortality rate associated with diabetes between 1970 and $1984 .{ }^{19}$ What is more, there is in fact now a cure for the disease - transplantation of portions of the pancreas (so long as one is willing to swap dependence on cyclosporine for dependence on insulin). Many animal studies preceded this clinical advance and accompany ongoing efforts to refine it. There is currently special interest in the use of fetal pancreatic tissue as a graft source; diabetic rats have been cured in this fashion. ${ }^{14}$ There are also attempts to induce regeneration of insulin-producing cells; interesting results have been achieved in rat 
models. And there is evidence of growing interest in the use of xenografts as sources of insulin producing tissue for diabetics. All this contains the promise that however damaging to the animal subjects involved, diabetes research is paying off for humans and that we may even be approaching effective therapies to end, rather than simply manage, the disease.

\section{Ethical Considerations}

So, it seems reasonable to regard diabetes research as something that it is prudent for our species to want. Is it something in which it is ethical for us to engage?

This is a huge problem, hinging as it does on such perennially contested questions as how best to reason about moral choice. My goal here is to show how restricting our attention to exemplary research focuses those questions. In particular, I will examine the bearing of utilitarian and nonutilitarian perspective on exemplary research.

Is diabetes research justified on utilitarian grounds? Like so many such questions, it's a difficult one to answer, especially as it requires not simply the interpersonal but the interspecific comparison of utilities. It seems very reasonable to believe that the actual experiments Banting and Best performed were not only a prudent expenditure of resources (from a human point of view) but even well-justified from an impartialist, consequentialist perspective. But this is really not the comparison we need to make. Apologists for research often claim that it is the whole institution that ought to be assessed, not each individual experiment - which seems fair enough. Accordingly, it isn't Banting and Best's extraordinary success that needs to be weighed against the suffering of their animals, but the entire stream of research which flows into and out of their work, with all its reefs and obstructions.

I want to raise three points about this question of the research's acceptability: one, that it is a real question, one that poses the vital interests of vast numbers of diabetics against those of many research animals: this isn't a matter of sacrificing animal interests for taste or fashion. Second, because it is a real question, it's a tough one to resolve from a utilitarian framework. A person can't simply recognize that nonhumans deserve equal consideration of interests, and immediately conclude that exemplary research is immoral, as one can perhaps concerning such horrors as maternal-deprivation studies. This leads me to my third claim: much will depend upon whether, and to what extent, the utilities available to typical humans are richer and more numerous than those available to typical nonhumans.

To raise this last point with respect to many kinds of animal exploitation seems to me to be just a way of asking whether humans are "utility monsters" - so enamored of the taste of animal flesh or the look of leather that our pleasure in it outweights the pain we inflict in order to get it. But I don't think that we need to distort our own nature quite so much to make the issue troubling in the context of exemplary research. Regan holds that humans typically have greater opportunities for satisfaction than do nonhumans; this is why death is by and large a greater harm for us than for them. ${ }^{15}$ Sapontzis, on the other hand, notes that the variant keenness of animal senses makes it possible that nonhumans may have lush avenues of enjoyment open to them which are altogether closed to us. ${ }^{16}$

I'm not going to try to adjudicate this dispute now. It seems to me that given what we know about animals and about diabetes, it wouldn't be irresponsible for a person to conclude that research on the disease was justified by the consequences. What is more troubling is the distribution of those consequences: one group humans - reaps virtually all the benefits. Another - nonhumans - bears virtually all the burden. ${ }^{17}$ If exemplary research is justified by utilitarianism, it is justified in a way that brings to life all the "textbook" refutations which allege that utilitarianism could in principle mandate a slave society.

This brings us to nonutilitarian considerations. We intuitively shy away from the idea that we are merely receptacles of utility, and utilitarians can provide us with lots of plausible consequentialist reasons why we can act and think of ourselves as though we were something more. But those protections break down for nonhumans, and indeed, for them, utilitarianism presents its coldest, most calculating side. But the notion 
that animals can be seen as mere receptacles is under serious pressure from all sides: "marginal case" arguments point to nonhumans' moral analogs with handicapped members of our own species; Sapontzis' work on the virtues points to analogs with our especially admirable conspecifics, ${ }^{18}$ and Regan and others have shown how and why such central properties as being the "subject of a life" also tie the value we bestow on ourselves much more closely to the value we should bestow on nonhumans. But I'm not going to argue for this, directly, either. Rather, I'm now going to proceed on the assumption that inclusion in an impartial utilitarian calculus does not exhaust what is of moral importance about animals and display the consequences for exemplary research.

If nonhumans, pace utilitarianism, are protected by rights to life and to freedom from unnecessary, nontrivial suffering, it might seem that abolitionism simply follows. But that inference is too quick. For one thing, not all nonhumans may possess the requisite characteristics to be rights-bearers, and it is at least possible that different individuals may possess their rights with different degrees of stringency. For another, we do not generally hold that the rights of human persons secure them from any possible infringement of their individual welfare, so that even if animals generally possess rights of equal stringency to those typically possessed by humans, their involvement in exemplary medical research is not necessarily ruled out.

Regan's position, which presents itself as an abolitionism, has suggestive implications for the first of these challenges. To develop them, some empirical information will be useful.

In 1988 the premier journal Diabetes reported 253 original experiments. Humans were the animal of choice; 109 of the studies, or $43 \%$, were performed on members of our species. Of the remaining 144 studies, 92 were performed on rats (including 7 on rat cell lines), and 31 on mice (including 2 on mice cell lines). Ten studies involved dogs; 3 involved chicks, rabbits or hamsters; and 3 involved other cell lines. ${ }^{19}$

The cell-line studies are the only ones that do not violate Regan's "rights view." He takes all the animals over a year of age to possess rights which protect them from this sort of experimentation, while the chicks and any of the other baby animals, who might have rights that could be violated by this usage, are given the benefit of the doubt and classified as rights-bearers.

$\prod$

t seems to me that given what we

know about animals and about

diabetes, it wouldn't be irresponsible for

a person to conclude that research on

the disease was justified by the

consequences. What is more troubling is

the distribution of those consequences:

one group - humans - reaps virtually all

the benefits. Another - nonhumans -

bears virtually all the burden. If exemplary

research is justified by utilitarianism, it is

justified in a way that brings to life all the

'textbook' refutations which allege that

utilitarianism could in principle mandate a

slave society.

The strength of this argument will vary contextually. Forbearing to use immature or nonmammalian animals in exemplary research on the grounds that they may be rights-bearers strikes me as very similar to the argument that we ought not to permit abortion because fetuses may be persons. The abortion argument overlooks the significance of the proposed restriction for 
women, of whose status as persons we are (or should be) sure. Analogously, forbidding research on Regan's grounds too cavalierly dismisses the moral significance of the victims of diabetes, and of other debilitating and deadly diseases.

Further, although Regan maintains that his view implies that all those who have inherent value have it equally, his argument for this position depends mainly on rejecting the commensurability of intrinsic and inherent value. Thus, the greater richness he is willing to attribute to typical human experience is a matter of intrinsic value, and hence not relevant to determining fundamental moral rights, which are a function of inherent value. But it seems very likely that the psychological abilities undergirding inherent value are themselves had in a graded fashion, so that inherent value may be realized differentially, as such things as desire, memory, preferences, and psychophysical identity over time are realized differentially in, say, rats and dogs.

The upshot of these considerations is that exemplary research, since it is plausibly seen as justified by utilitarian considerations, might avoid running afoul of nonutilitarian constraints by ceasing to use certain animal models. Among its nonconsenting subjects, diabetes research relies heavily on rodents. Perhaps work on dogs and primates ought to be eliminated, and only studies involving (preferably immature) rats and mice continue, as such animals may have lesser inherent value.

But even if all animals used in exemplary research have equally stringent rights, there is still reason to question whether complete abolition of all research on nonconsenting subjects is morally necessary.

Quite a strong case might be marshalled for abolition of invasive medical research on young children. If we agree that children ought to be regarded as ends-in-themselves, or anyway as protected by some such "deontological stop," then an appeal to benefits gained can't solely justify the interventions; if we regard parental prerogatives as justified solely by the parents' contribution to their children's good, then any proxy consent on the part of a parent oversteps allowable limits, since it may expose the child to risk and danger in a cause that is not directly in the child's interests. ${ }^{20}$ Yet pediatric research goes on - not, I think because of a social judgment that children don't count for much morally, but rather because parental discretion is taken to range further than assumed in the above position.

It has, in my view, been persuasively argued that parents have the right to consent on behalf of their children to participate in low-risk, mildly invasive research, on the grounds that children are members of the community to whose weal the information is designed to contribute. They are not freely floating atoms, but part of a social whole; in part, at least, their good is a function of its good. Thus, they are not simply means to its ends; the ends of each overlap. ${ }^{21}$ Current federal guidelines allow participation in studies involving more than minimal risk, and which offer no direct benefit to the child; parental proxy consent must be supplemented by an institutional review board, which must determine that the knowledge sought is indeed significant and that the risk is not too great. ${ }^{22}$

Does this suggest that nonhumans might at least be exposed to the same degree of invasiveness, suffering, and risk in exemplary research as that to which we are willing to expose our children? Clearly, the disanalogous feature is the roles that children and animals occupy in our socicty outside of the research context. This point is also germane to assessing the relevance of relying on involuntary conscription as a strategy for justifying exemplary research.

H.J. McCloskey has used this idea in the course of arguing that, even granting that nonhuman mammals have rights of the kind for which Regan argues, nothing very challenging follows for exemplary research..$^{23} \mathrm{He}$ directs our attention to the infamous case in which Regan supposes a dog to be stranded with four humans in a lifeboat. If somebody needs to be tossed over so that all the rest can survive, generally, Regan says, the dog ought to go. McCloskey sees this as committing Regan to the view that the rights to life of moral agents as such are more stringent than those of moral patients and continues, 
it is not only the right to life of persons that may outweigh the right to life of a dog. The rights to health, to bodily integrity, to selfdevelopment of persons, as rights of recipience, may outweigh the rights of mammals such as dogs to life, and freedom from suffering.

Hence, granted that mammalian rights are prima facie rights of recipience, the

flood-gates are opened to justify animal experimentation that is scientifically and ethically well-planned, to secure for persons the enjoyment of the more stringent rights of persons, at the expense of the less stringent rights of mammals. ${ }^{24}$

He concludes that using animals as experimental subjects would not therefore be treating them as "mere receptacles" but rather as though they were fairly chosen conscripts facing death and injury in a just war.

Now, as a piece of internal criticism of the rights view, this seems way off the mark. Regan's belief that one could dump a million dogs off the lifeboat to save one person doesn't hinge on any general position about moral agents and moral patients but rather about the relevance of unequal harms faced by the possessors of equally stringent rights. Nor does it seem at all clear how, even if moral agents had some advantage over moral patients regarding the stringency of their right to life, it would follow that all their other moral rights could trump the right to life of moral patients.

But McCloskey's final point remains of some interest, for involuntary conscription, like pediatric research, need not be based on any belief about the lack of stringency of the rights of children or conscripts. McCloskey's concern is to justify the "special place" that animals are to have in this system of conscription by virtue of their lesser rights. Mine is to explore what the general conditions on justified involuntary commitment imply for research on the assumption that the moral status of relevant nonhumans is equivalent to that of humans.

Involuntary conscription may outrage libertarian sentiments, but it does seem that commu-

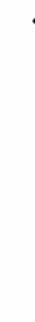

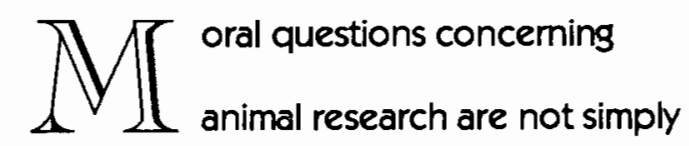

questions about what ought or ought not

to go on in laboratories. These are

questions for all of us who benefit from

contemporary health care. If we want

these benefits to continue, we may have

to participate ourselves in the research

process that produces them and at the

same time make nonhumans a part of the

moral community to whose good their

sacrifices contribute.

nities may face serious threats which can only be met through conscription of its members. Imagine the appearance of a variant of AIDS which spread on casual contact and which did not observe species barriers. I can see no serious objection to conscripting both humans and nonhumans as research subjects in an effort to cure the disease (which is not at all the same thing as saying that researchers would have carte blanche with their conscripts).

What of situations where it isn't so clear that nobody has anything much to lose? Even in those cases, I think, we're generally disposed to countenance conscription in the face of grave dangers, when there is no practical way less restrictive of liberty to meet the danger.

But while these conditions are probably necessary for justifying the involuntary conscription of rights-bearers, they are surely not sufficient.

It may be instructive to look to the "just war" tradition to illuminate the character of a threat to which conscription is a defensible response. 
Just war theory attempts to present and defend conditions which justify trumping the rights of others to life and to the enjoyment of their property. It may be that in current contexts, or even categorically, the burden of justifying war is too great for those conditions to bear. But even so, they may still be useful as guidelines for trumping the rights of individuals involved in nonvoluntary participation in medical research. Two aspects of the tradition seem especially relevant: the insistence that the war in question be winnable, and the condition of proportionality. ${ }^{25}$

Both of these conditions are intended to avoid moral waste: the violence and other destruciveness associated with a war are not justifiable unless the good aimed at is in fact attainable, and no more such evils are justified than are absolutely necessary to attain the end.

It might seem that the conditions are too vague to guide practice, but I think that need not be so. Exemplary research's insistence on a demonstrable record of achievement in using animal models to ameliorate disease coheres nicely with the first of them and reinforces the condition as a selection criterion for the kinds of diseases against which invasive animal-based research may be employed; concern with proportionality underscores the need to press on with refinement, reduction, and replacement strategies.

Proportionality may also have an impact on species selection. If, for example, one accepts the suggestion that members of different species will typically suffer different degrees of harm in being restrained, or in dying, this condition would insist on the use of those species which will suffer the least. A proportionality condition might therefore bolster the distribution of species typical of diabetes research and might dovetail with suspicions about the unequal stringency of animal rights to support a virtual ban on the use of animals other than rodents in research.

There are other reasonable requirements: equity in the assignment of burdens, compensation for those who have served. And always, the rights of conscripts must be respected insofar as such respect is compatible with meeting the threat that generates conscription in the first place.

But before these conditions come into play, a more fundamental and much more problematic condition would have to be satisfied: all the conscripts must belong to the community being threatened, in the sense that individual and community interests are in large measure shared, as in the justification for pediatric research.

What motivates these conditions generally is the need to make a real distinction between serving the community as a slave and serving it as a conscript. In McCloskey's conception the assertion that animals used in research are rights-holders has no apparent significance; they are treated solely as means to ends in which they have no stake. Things are different for those justly conscripted to serve the community, whether they be children in pediatric research or soldiers fighting in a just war (if any there be); these individuals have an interest in the community's maintenance and development.

Now, if Regan and others who hold to a strong equivalence between the moral status of persons and animals are right, then research - even invasive, sometimes lethal research - might still be permissible. But the character and the context of that research would have to alter drastically. We would have to see ourselves as a community fully mobilized against disease, one which regarded diabetes, cancer, AIDS, and so forth as enemies against which we were prepared to direct the paths of our lives, not simply to contribute money. But even if McCloskey is right, and moral patients enjoy less stringent rights than do moral agents, it does not follow that casting research subjects in the role of conscripts will open any floodgates. For if research is to be justified on these grounds, we are still faced with the challenge of making animals a part of the community to whose weal their sacrifice contributes. Otherwise, we treat them as if they were mere receptacles of value, not valuable in themselves.

Making animals members of this community would be an immense task, and I am not sure exactly what would constitute success. Minimally, bringing about some substantial identity of interests between humans and nonhumans would require ending their exploitation at our hands for food, clothing, and entertainment and taking their interests seriously into account in making public policy decisions that affect them. 
Even granted such sweeping changes, it may seem that the situation of human conscripts is too importantly different from those of animals to justify the analogy. Conscripted soldiers, for example, presumably feel an identification with their community. There are likely to be individuals at home for whom they care, but even if not, they may well have a regard for the institutions, the traditions, and the values which characterize their society. It may not be too fanciful to say that their own identities are constituted, in part, by their community membership.

This kind of identification with individuals and values isn't possible for nonhumans; their psychologies just don't work that way. But neither is it possible for very young children. They, of course, may come to care about their communities in ways nonhumans cannot. But if this is so, it is likely to be because they will in fact benefit from its flourishing. So perhaps it is not the intensional state of caring about a community that's key but the actual benefits that conscripts receive from their community.

It's sometimes said that what animals really need from us is simply to be left alone, but given the impact of our species upon this planet, this is probably too simple. And even were this not the case, leaving animals alone is a radical departure from our current practices and would involve considerable forbearance on our part. A society of that kind would be one in whose maintenance animals would have an interest. And although the kind of health enhancement to which even exemplary medical research would contribute might not advance those interests further, it is probably not in general necessary that conscripts be personally benefitted by the contributions they make. That a community is so structured as to respect the rights of its members may itself be sufficient grounds to see the interests of individuals and the community as something they hold in common.

Furthermore, if the enterprise of research medicine is really so important to us, we may have to impose some kind of nonvoluntary participation in research by humans as well. Equity does not demand identical treatment, of course; there are differences in vulnerabilities among species which would make subjecting humans (or monkeys) to the kind of confinement and rigors undergone by rodents altogether inequitable. But if we have to look solely to involuntary conscription as a means of overcoming the presumption against using animals as means to our ends, we may have to demonstrate our good faith by participation in the process ourselves.

\section{Conclusion}

Ethical investigation of the use of animal models in research at once needs to become more fine-grained and more expansive in scope. We would do well to pay closer attention to the ways in which such an en terprise as diabetes research differs from, say, toxicity testing or pain research. We ought also to learn more about the particular character of specific animal models.

But we should remember as well that the moral questions concerning animal research are not simply questions about what ought or ought not to go on in laboratories. These are questions for all of us who benefit from contemporary health care. If we want these benefits to continue, we may have to participate ourselves in the research process that produces them and at the same time make nonhumans a part of the moral community to whose good their sacrifices contribute. ${ }^{26}$

\section{Notes}

\footnotetext{
${ }^{1}$ H.J. McCloskey, "The Moral Case for Experimentation on Animals," The Monist 70, no. 1 (January 1987).

${ }^{2}$ See, for example Victor Fuchs, Who Shall Live? (New York: Basic Books, 1975).

${ }^{3}$ Fred Davison, "Historical Perspectives of Biomedical Experimentation," in Institute of Laboratory Animal Resources, The Future of Animals, Cells, Models, and Systems in Research, Development, Education and Testing (Washington, D.C.: National Academy of Sciences, 1977), p. 12, as quoted in Michael A. Fox, The Case for Animal Experimentation (Berkeley and Los Angeles: The University of California Press, 1986), pp. 94-95.
}

"Sidney Gendin, "The Use of animals in Science," in Animal Sacrifices, ed. Tom Regan (Philadelphia: Temple University Press, 1986).

${ }^{5}$ McCloskey, p. 69.

${ }^{6}$ Dallas Pratt, Painful Experiments on Animals (New York: Argus Archives, 1976), as cited in Gendin, p. 42. 
${ }^{7}$ Michael Bliss, The Discovery of Insulin (Chicago: University of Chicago Press, 1982), p. 39.

${ }^{8}$ Charles Best, "A Short Essay on the Importance of Dogs in Medical Research," The Physiologist, 17, no. 4 (November 1974), as cited in Bliss.

${ }^{9}$ See Peter Singer, "Animal Experimentation: Philosophical Perspectives," The Encyclopedia of Bioethics, Vol. 1 (New York: The Free Press, 1978), p. 80, and Andrew Roan, OfMice, Models and Men (Albany: SUNY Press, 1984), p. 181.

${ }^{10}$ Maureen Harris and Paul Entmecher, "Mortality from Diabetes," in National Diabetes Data Group, Diabetes in America (National Institutes of Health Publication No. 851468 , August, 1985), chapter 29.

"Janice Dorman and Ronald LaPorte, Mortality in InsulinDependent Diabetes," in Diabetes in A merica, chapter 30.

${ }^{12}$ See, for discussion of all these models, Diabetes Vol. 31. Supplement 1 (April 1982), special issue reviewing the use of animal models in diabetes research.

${ }^{19}$ Harris and Entmecher, "Mortality from Diabetes."

${ }^{14}$ See Charles M. Peterson et ah, "Perspectives on the Use of Human Fetal Tissue in the Field of Research on Diabetes Mellitus: An Introduction," in Charles M. Peterson et al,eds., Fetal Islet Cell Transplantation: Implications for Diabetes (New York: Springer Verlag, 1988), p. 1.

${ }^{15}$ Tom Regan, The Case for Animal Rights (Berkeley and Los Angeles: University of California Press, 1983), p. 324.

${ }^{16}$ S.F. Sapontzis, Morals, Reason and Animals (Philadelphia: Temple University Press, 1987), p. 219.

${ }^{17}$ For a development of this line of reasoning, see Lawrence Finsen, "On Being Subjected to Research: Fxploring Neglected Analogies," presented to the Pacific Division American Philosophical Association, March, 1984.

${ }^{18}$ See S.F. Sapontzis, "Are Animals Moral Beings?" American Philosophical Quarterly 17 (1980).

${ }^{19}$ Information taken from a study by Professor Cyprian Weaver, OSB.

${ }^{20}$ See Paul Ramsey, "Consent as a Canon of Loyalty with Special Reference to Children in Medical Investigation," in Tom Beauchamp and LeRoy Walters, eds., Contemporary Issues in Bioethics (Encino, California: Dickenson, 1978), pp. 453-456.

${ }^{21}$ See Richard McCormick, "Proxy Consent in the Experimentation Situation," in Beauchamp and Walters, Pp. 457-464.

${ }^{22}$ The relevant Department of Health and Human Services guidelines are discussed in Baruch Brody and Tristram Englehardt, eds., Bioethics: Readings and Cases (Englewood Cliffs, New Jersey: Prentice Hall, 1987), pp. 266-267.

29 McCloskey, p. 80.

${ }^{24}$ Ibid.
${ }^{25}$ See the discussion in Ralph B. Potter, War and Moral Discourse (Richmond, Virginia: John Knox Press, 1973), especially chapter 5 .

${ }^{26}$ Research on this paper has been aided by a grant funded by the National Science Foundation and the National Institute of Arthritis, Diabetes and Digestive and Kidney Diseases of the National Institutes of Health. I am also grateful for the close attention of Lawrence Finsen, Richard Fenn and Hilde L. Nelson.

\section{$\Rightarrow+1$}

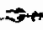

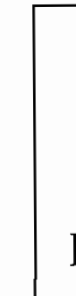

Rainbows of fish,
streamers of dolphins.

A celebration for the world.

Pods of whales breaching,

great hands splashing

in a bowl of diamonds.

Shadows on the forest carpet

were just the wings of eagles.

The redwood had no enemies.

Velvet cats walked the night.

Elephants and wolves had nothing to fear.

Weavings of jungle and swamp abandoned on the loom.

Home only to those who belonged

there.

Water was clean, air was visible.

Earth was colonized by flowers.

No one here can remember,

but it must have been quite a time.

- Kathleen Malley 